\title{
Core evolution driven by mantle global circulation
}

\author{
${ }_{2} \quad$ Peter Olson $^{a *}$ Renaud Deguen ${ }^{b}$, Maxwell L. Rudolph ${ }^{c}$, Shijie Zhong ${ }^{d}$ \\ ${ }^{a}$ Department of Earth and Planetary Sciences, Johns Hopkins University, Baltimore, MD, USA \\ ${ }^{b}$ LGL, Laboratoire de Géologie de Lyon, CNRS, Université Lyon 1, Villeurbanne, France \\ ${ }^{c}$ Department of Geology, Portland State University, Portland, OR, USA \\ ${ }^{d}$ Department of Physics, University of Colorado, Boulder, CO, USA
}

\section{Revised for Physics of the Earth and Planetary Interiors}

March 10, 2015

\begin{abstract}
Reconstructions of the Phanerozoic history of mantle global circulation that include past plate motions are used to constrain the thermochemical evolution of the core. According to our mantle global circulation models, the present-day global average heat flux at the core-mantle boundary lies in the range $80-90 \mathrm{~mW} . \mathrm{m}^{-2}$, with peak-to-peak, long wavelength lateral variations up to $100 \mathrm{~mW} \cdot \mathrm{m}^{-2}$ associated with compositional and thermal heterogeneity in the D"-layer. For core thermal conductivity in the range $k=100-130 \mathrm{~W} \cdot \mathrm{m}^{-1} \cdot \mathrm{K}^{-1}$ we infer that the present-day outer core is thermally unstable beneath the high seismic velocity regions in the lower mantle but thermally stable beneath the large low seismic velocity provinces. A numerical dynamo shows how this boundary heat flux heterogeneity generates departures from axial symmetry in the time average geomagnetic field and the pattern of flow in the outer core. Standard thermochemical evolution models of the core driven by mantle global circulation heat flow predict inner core nucleation between 400 and 1100 Ma. With thermal conductivity $k \simeq 100 \mathrm{~W} \cdot \mathrm{m}^{-1} \cdot \mathrm{K}^{-1}$ the core heat flow derived from our mantle global circulation models is adequate for maintaining the geodynamo since inner core nucleation, supercritical for dynamo action by thermal convection just prior to inner core nucleation, and marginal for inner core convection.
\end{abstract}

* Corresponding author: Peter Olson; e-mail address: olson@jhu.edu

Keywords: Mantle Global Circulation, Inner Core Age, Core Evolution, Geodynamo 


\section{${ }_{24} 1$ Introduction}

25 The geodynamo owes its existence to convection in the mantle. The rate of energy release 26 required to maintain the geodynamo at its present-day intensity over geologic time is so large ${ }_{27}$ - on the order of 10-16 TW (terawatts) - that it would likely have ceased to operate long ago ${ }_{28}$ were it not for the heat extracted from the core by the circulation of the mantle. Estimates 29 of the energy required by the geodynamo as well as estimates of the actual heat loss from 30 the core have recently been revised upward, partly in response to recent studies indicating 31 the thermal conductivity of core alloys is higher than previously assumed (de Koker et al., 2 2012; Pozzo et al., 2012; Gomi et al., 2013; Zhang et al., 2015), and partly because the 33 radial structure and the amount of lateral heterogeneity in the D" region near the base of 34 the mantle imply that the heat flow from the core is large (Buffett, 2007; Hernlund, 2010; 35 Zhang and Zhong, 2011; Wu et al., 2011).

36 37

The combination of higher thermal conductivity and high core heat flow implies that the rate at which the core evolves is also fast in comparison with what would be the case were these properties smaller. An often-used metric for core evolution is the rate of growth of the solid inner core. Assuming the inner core boundary is at the melting point and the outer core is well mixed, growth of the inner core by solidification must track the cooling of the core as a whole (Labrosse, 2003; Buffett, 2003). In addition, the inner core growth contributes directly to maintaining the geodynamo through release of buoyant lighter elements, driving thermochemical convection in the liquid outer core (Jones, 2007).

Major problems for quantifying the energy budget of the core and its rate of evolution stem from uncertainties in the core-mantle boundary (CMB) heat flow, the melting curve in the core (Andrault et al., 2011; Anzellini et al., 2013), the partitioning of light elements at the inner core boundary (Gubbins et al., 2004; Nimmo and Alfe, 2006), and the amount of radioactive heat production in the core (Gessmann and Wood, 2002; Murthy et al., 2003; Bouhifid et al., 2007; Hirose et al., 2013). Among these parameters, the CMB heat flow is probably the most important and is certainly the most complex, because the local heat flux is inhomogeneous on the CMB and the total heat flow from the core varies with time.

All estimates of the present-day core heat flow are all based on indirect methods; these include calculation of mantle plume fluxes, consideration of dynamo thermodynamics, interpretations of lower mantle seismic structure, and output from mantle global circulation 
models (hereafter referred to as mantle GCMs). Mantle plume flux calculations based on hotspot activity initially yielded small values, in the range of $Q_{c m b}=2-5$ TW (Loper, 1978; Davies, 1988; Sleep, 1990; Stacey and Loper, 2007) for the total core-mantle boundary heat flow, although later improvements to these estimates (Labrosse, 2002) yielded $Q_{c m b} \simeq 13$ TW (Leng and Zhong, 2008). Estimates derived from the thermodynamics of the geodynamo yield somewhat higher values, generally in the range $Q_{c m b}=4-10 \mathrm{TW}$ (Buffett et al., 1996; Buffett, 2002; Labrosse, 2003; Gubbins et al., 2004). Interpretations of the seismic structure in the D" region at the base of the mantle in terms of post-perovskite phase changes yield significantly higher values, with average heat flux in the range $\bar{q}_{c m b}=65-100 \mathrm{~mW} \cdot \mathrm{m}^{-2}$ (Lay et al., 2006; van der Hilst et al., 2007; Monnereau and Yuen, 2010; Wu et al., 2011) equivalent to a total core heat flow of $Q_{c m b}=10-16 \mathrm{TW}$, although Tateno et al. (2009) obtained $Q_{c m b}=6 \mathrm{TW}$ with this approach. Interpretations of the lateral heterogeneity in the seismic structure also provide estimates of the lateral heterogeneity in CMB heat flux in the range of $q_{c m b}^{\prime}=20-50 \mathrm{~mW} \cdot \mathrm{m}^{-2}$ (van der Hilst et al., 2007; Lay et al., 2008). Not surprisingly, such a wide range of the core heat flows yield a comparably wide range for the age of inner core nucleation, hereafter abbreviated ICN. The lower core heat flow estimates predict ICN ages in excess of $2.5 \mathrm{Ga}$, whereas the higher estimates predict ICN ages around $0.5 \mathrm{Ga}$ (Labrosse et al., 2001; Roberts et al., 2003; Nimmo, 2007). Adding to this uncertainty, the CMB heat flow is time dependent, yet there is little by way of direct observational constraints on how much it has varied since the ICN.

Dynamically based predictions for the time variation of the average core heat flow and its lateral heterogeneity can be extracted from mantle GCMs. The CMB heat flow in these models depends on many parameters, including the lower mantle viscosity, thermal conductivity, and the thermal gradient in the D" region, the latter depending on the strength of the circulation in the lower mantle, the compositional stratification, phase changes in D" such as post-perovskite (Nakagawa and Tackley, 2011), and the presence or absence of smaller scale instabilities in that region (Nakagawa and Tackley, 2010; Zhang et al., 2010; Zhang and Zhong, 2011). Uncertainties in these mantle properties, as well as the non-uniqueness in the surface plate reconstructions that are often used as upper boundary conditions lead to substantial uncertainty in mantle GCM predictions.

However, mantle GCMs can be tuned to match the present-day surface heat flow and can also be tuned to match the present-day internal structure of the mantle, reducing their 
uncertainty somewhat. In this connection, the structure of dense chemical piles in the lower mantle offers an important geodynamical constraint on core heat loss. It is found that very high $\mathrm{CMB}$ heat flow is required to maintain compositionally dense piles the size of the two large low shear velocity provinces (LLSVPs) seen in the present-day lower mantle seismic structure (McNamara and Zhong, 2004). Depending on the values of other mantle parameters, maintaining two dense piles comparable in size to the LLSVPs requires a mean CMB heat flux of $\bar{q}_{c m b}=75-100 \mathrm{~mW} \cdot \mathrm{m}^{-2}$ and peak-to-peak, long wavelength lateral variations up to $100 \mathrm{~mW} \cdot \mathrm{m}^{-2}$ (Nakagawa and Tackley, 2008; Zhang and Zhong, 2011; Olson et al., 2013).

In this paper we use statistics of the global mean CMB heat flow and lateral variations of CMB heat flux obtained from plate-driven mantle GCMs that generate lower mantle chemical piles similar to those observed in the lower mantle to calculate the thermal evolution of the core backward in time, starting from the present-day and continuing to the time of ICN. We also use the present-day pattern and magnitude of CMB heat flux from one of these mantle GCMs to drive a numerical dynamo model, linking the structure of the dynamoproduced magnetic field and lateral heterogeneity within the outer core to the global mantle circulation.

\section{Mantle global circulation and core heat flux}

Mantle global circulation models provide self-consistent relationships between dynamical properties of the mantle such as plate spreading rates, viscosity, and radioactive heat production and core heat flux, and observables such as mantle heterogeneity and heat flux at the surface (McNamara and Zhong, 2005). In some mantle GCMs the circulation is entirely free convection driven by thermal and compositional buoyancy (Nakagawa and Tackley, 2013, 2014). In others, the circulation is a combination of forced convection driven by prescribed surface plate motions plus free convection (McNamara and Zhong 2005; Zhang et al., 2010; Zhang and Zhong, 2011; Bower et al., 2013; Bull et al., 2014; Rudolph and Zhong, 2014). A commonly-used procedure in these models is to adjust the Rayleigh number governing the free convection part of the circulation to match some global constraint, such as zero net torque on the surface plates or equal r.m.s. velocity of the free and forced components of the flow. 
Table 1 gives the input parameters of the mantle GCM used in this study. In addition to transport and thermodynamic parameters, the mantle GCM depends on the prescribed surface plate motions. Here we have used four paleoplate reconstructions. Case 1 uses the reconstruction by Muller et al. (2008) covering the period 0-140 Ma; Case 2 uses the reconstruction by Lithgow-Bertelloni and Richards (1998) covering the period 0-119 Ma; Case 3 uses the reconstruction by Seton et al. (2012) covering 0-200 Ma. Each case has identical initial conditions, including an initially $250 \mathrm{~km}$ thick dense layer at the base of the mantle, with properties listed in Table 1. Each case started at $608 \mathrm{Ma}$, with the first 150 Myr as a spin-up phase. The spin-up phase was initiated using a horizontally uniform temperature field taken from a pre-calculation run to statistically steady state with rms surface velocity chosen to match the rms velocity of the first (450 Ma) stage of the Zhang et al. (2010) 450-119 Ma proxy plate reconstruction. Our Case 2 is identical to the reference case FS1 in Zhang et al. (2010) and to Case HF1 from Zhang and Zhong (2011). It is also the same as Case 2 in Rudolph and Zhong (2014). Our Cases 1 and 3 are identical to our Case 2 except for the plate motions over the last 200 Ma in our Case 3 and over the last $140 \mathrm{Ma}$ in our Case 1, for which Seton et al. (2012) and Muller et al. (2008) are used, respectively.

We use temperature-dependent viscosity $\eta$ with a depth-dependent viscosity prefactor of the form

$$
\eta=\eta_{0} \exp \left(E^{*}\left(0.5-T^{*}\right)\right)
$$

where $\eta_{0}$ is a depth-dependent viscosity prefactor, $E^{*}$ controls temperature-dependence and $T^{*}$ is non-dimensional temperature, which varies from 0 at the surface to 1 at the CMB. We use $E^{*}=9.21$, leading to variations in viscosity of four orders of magnitude from temperature variations. We include a 30-fold decrease in viscosity prefactor at $150 \mathrm{~km}$ depth, a uniform viscosity prefactor in the upper mantle and transition zone, a factor of 60 increase in viscosity prefactor at $670 \mathrm{~km}$ depth, and a linear increase in viscosity prefactor across the lower mantle leading to an overall factor of 3.4 increase. This viscosity structure is identical to that used in Rudolph and Zhong (2014) Case 2, Zhang et al. (2010) Case FS1, and Zhang and Zhong (2011) Case HF1. We use a numerical resolution of $64^{3}$ elements on each of the 12 caps of the CitcomS mesh with refinement in the radial direction in boundary layers.

Figure 1 shows the variation in the global average CMB heat flux $\bar{q}_{c m b}$ versus age from three mantle GCMs calculated using three plate tectonic reconstructions as surface boundary 
conditions. Figure 1 also shows heat flux patterns on the CMB at four distinct times in the Phanerozoic from mantle GCM Case 2. The continent locations are shown in shadow, and convergent and divergent plate boundaries are shown by solid and dashed lines, respectively (Zhang et al., 2010). These images represent the longest-wavelength components of the CMB heat flux heterogeneity, represented by spherical harmonic degrees 1-4.

Several points are worth noting here. First, the present-day CMB heat flux pattern in Figure 1a is dominated by the spherical harmonic degree 2 structure that is prominent in lower mantle seismic tomography (Romanowicz and Gung, 2002; Dziewonski et al., 2010; Lekic et al. 2012). High heat flux is distributed along an approximately great circle band passing beneath the eastern parts of the Americas and Asia. Low heat flux occurs in two regions, one beneath Africa the other beneath the central Pacific, closely coincident with the seismically observed LLSVPs. In terms of the dynamics of the lower mantle, the high CMB heat flux belt corresponds to lower mantle downwellings where lithospheric slabs descend toward the CMB; the low CMB heat flux regions correspond to lower mantle upwellings above the dense chemical piles, which have been implicated as sites of deep mantle plume formation (Burke and Torsvik, 2004; Burke et al., 2008; Torsvik et al., 2006). In contrast, at $275 \mathrm{Ma}$ in Figure 1 the CMB heat flux is dominated by a spherical harmonic degree 1 pattern, with mostly high heat flux beneath the margins of supercontinent Pangaea produced by major downwellings originating at convergent plate margins arrayed around the edge of the supercontinent. This spherical harmonic degree 1 pattern is partially disrupted around 180 Ma by the breakup of Pangaea and is further disrupted by opening of the Atlantic, so that by 110 Ma the CMB heat flux pattern is dominated by a spherical harmonic degree 2 very similar to the present-day.

The present-day global mean CMB heat flux in Figure $1 \mathrm{~b}$ is $\bar{q}_{c m b}=86 \mathrm{~mW} \cdot \mathrm{m}^{-2}$, less than the $q_{a d} \simeq 100 \mathrm{~mW} \cdot \mathrm{m}^{-2}$ conducted down the core adiabatic gradient if we assume a high value of $k=130 \mathrm{~W} \cdot \mathrm{m}^{-1} \cdot \mathrm{K}^{-1}$ for the thermal conductivity in the outer core below the CMB (corresponding to about $15 \mathrm{TW}$ total core heat flow). The difference between the global mean CMB heat flux and adiabatic conduction suggests the presence of stable thermal stratification in the outer core beneath the CMB, with the possibility that thermal convection might be suppressed there. However, it is necessary to take into account the lateral heterogeneity in CMB heat flux produced by the lower mantle convection. The hatched contours in Figure 1 enclose regions where the local CMB heat flux $q_{c m b}$ exceeds $100 \mathrm{~mW} \cdot \mathrm{m}^{-2}$; these regions 
cover nearly $40 \%$ of the CMB at the present-day, nearly $45 \%$ at $110 \mathrm{Ma}$, and about $30 \%$ at $275 \mathrm{Ma}$, respectively. Within these regions the local CMB heat flux is expected to exceed the heat conducted down the outer core adiabat even if the thermal conductivity of the outer core is as high as $130 \mathrm{~W} \cdot \mathrm{m}^{-1} \cdot \mathrm{K}^{-1}$. The reverse situation applies in regions outside the hatched contours; there we expect stable thermal stratification beneath the CMB if the thermal conductivity is high. Whether or not such a patchwork of superadiabatic and subadiabatic heat flux supports a global layer with stable stratification beneath the CMB remains an open question. Buffett (2014) has interpreted the geomagnetic secular variation in favor of global thermal stratification beneath the CMB, whereas Amit (2014) came to the opposite conclusion using the same data. Another possibility is compositional stratification due to light element gradients in this region (Helffrich and Kaneshima, 2010), which could be far more stabilizing than purely thermal stratification.

\section{Heterogeneous core-mantle boundary heat flux and the present-day geodynamo}

We model the influence of the general circulation of the mantle on the present-day state of the geodynamo by applying the CMB heat flux pattern shown in Figure 1a to a numerical dynamo driven by the coupled effects of CMB heat flux and chemical differentiation at the inner core boundary associated with inner core growth. The standard approach to modeling Boussinesq thermochemical convection in the outer core involves the co-density variable

$$
C=\rho_{o c}(\alpha T+\beta \chi)
$$

where $\rho_{o c}$ is average outer core density, $T$ is the outer core temperature relative to the adiabat, $\chi$ is the outer core light element concentration, and $\alpha$ and $\beta$ are volumetric expansivities for $T$ and $\chi$, respectively. At the CMB we specify the heat flux as the sum of a global mean part $\bar{q}_{c m b}$ and a laterally varying part $q_{c m b}^{\prime}$ :

$$
q_{c m b}=\bar{q}_{c m b}+q_{c m b}^{\prime}(\phi, \theta)
$$

where $\phi$ and $\theta$ are longitude and co-latitude, respectively. $\bar{q}_{c m b}$ is to be compared with the heat conducted down the core adiabat $q_{a d}$, such that $\bar{q}_{c m b}-q_{a d}>0$ corresponds to superadiabatic heat flux in the Boussinesq approximation. The function $q_{c m b}^{\prime}$ in (3) specifies the amplitude and the planform of the CMB heat flux heterogeneity. 
Writing the codensity as the sum of global mean and laterally varying parts $C=\bar{C}+C^{\prime}$, we express the CMB heat flux (3) as

$$
\left.\frac{\partial \bar{C}}{\partial r}\right|_{\mathrm{cmb}}=-\frac{\rho_{o c} \alpha\left(\bar{q}_{c m b}-q_{a d}\right)}{k} ;\left.\quad \frac{\partial C^{\prime}}{\partial r}\right|_{\mathrm{cmb}}=-\frac{\rho_{o c} \alpha q_{c m b}^{\prime}}{k}
$$

where $k$ is the outer core thermal conductivity. At the inner core boundary (ICB) we assume constant codensity $C=C_{i c b}$.

We take $\bar{q}_{c m b}$ and $q_{c m b}^{\prime}$ from Figure 1a and convert these to codensity boundary conditions using (4). We nondimensionalize these boundary conditions for input into the numerical dynamo using the difference between $\mathrm{CMB}$ and $\mathrm{ICB}$ radii $D=r_{c m b}-r_{i c b}$ and $D^{2} / \nu$ to scale length and time, respectively, and $\rho_{o c} \beta D^{2} \dot{\chi} / \nu$ to scale co-density, where $\nu$ is outer core kinematic viscosity and $\dot{\chi}$ is the time rate of change of the light element concentration in the outer core due to inner core growth, which is the main source of buoyancy for outer core convection. This choice of scaling produces the following dynamo control parameters (Olson et al., 2013): the compositional Rayleigh number and Ekman number

$$
R a=\frac{\beta g D^{5} \dot{\chi}}{\kappa \nu^{2}} ; \quad E=\frac{\nu}{\Omega D^{2}}
$$

where $g$ is gravity at the CMB and $\Omega$ is the angular velocity of rotation, plus the Prandtl and magnetic Prandtl numbers

$$
\operatorname{Pr}=\frac{\nu}{\kappa} ; \quad \operatorname{Pm}=\frac{\nu}{\eta}
$$

where $\kappa$ is diffusivity for the codensity. The heat flux boundary conditions at the CMB (4) are given in terms of the dimensionless codensity (denoted with asterisks) as

$$
\left.\frac{\partial \bar{C} *}{\partial r *}\right|_{\mathrm{cmb}}=-\frac{R a_{q}}{R a} ;\left.\quad \frac{\partial C^{\prime} *}{\partial r *}\right|_{\mathrm{cmb}}=-\frac{R a_{q^{\prime}}}{R a} f^{*}
$$

where the Rayleigh numbers based on CMB heat flux are defined as

$$
R a_{q}=\frac{\alpha g D^{4}\left(\bar{q}_{c m b}-q_{a d}\right)}{\nu \kappa k} ; \quad R a_{q^{\prime}}=\frac{\alpha g D^{4} \delta q_{c m b}}{\nu \kappa k}
$$

with $\delta q_{c m b}=\max \left(q_{c m b}^{\prime}\right)-\min \left(q_{c m b}^{\prime}\right)$ and $f^{*}=q_{c m b}^{\prime} / \delta q_{c m b}$.

Figures 2, 3, and 4 show snapshots and time averages of the structure of a thermochemical numerical dynamo defined according to (2-8) with Rayleigh number $R a=4 \times 10^{6}$, Ekman number $E=10^{-4}$, Prandtl number $\operatorname{Pr}=1$, magnetic Prandtl number $P m=6, \epsilon=-1.47$ for 
the codensity sink (see Supplementary Materials), plus the CMB heat flux from Figure 1a with $R a_{q} / R a=-0.08$ and $R a_{q^{\prime}} / R a=0.1$, corresponding to an assumed $q_{a d}=100 \mathrm{~mW} \cdot \mathrm{m}^{-2}$ from $k=130 \mathrm{~W} \cdot \mathrm{m}^{-1} \cdot \mathrm{K}^{-1}$ in the outer core. The numerical dynamo code (MagIC; Wicht, 2002) used 81, 128, and 256 outer core grid points in radius, latitude, and longitude, respectively, 9 radial points in the inner core, and spherical harmonic truncation at degree and order 85. Time averages were computed over 10 magnetic dipole diffusion times, corresponding to roughly $500 \mathrm{kyr}$ in the core. No polarity reversals were recorded.

Figure 2 shows a snapshot of the radial component of the magnetic field on the CMB from the numerical dynamo, compared with the radial component of the modern geomagnetic field on the CMB from core field model POMME 2008 truncated at spherical harmonic degree and order 12. Contours of the geomagnetic field are in millitesla; contours of the dynamo field are in dimensionless Elsasser number units $\sigma B^{2} / \rho_{o c} \Omega$, where $\sigma$ is the electrical conductivity of the core and $B$ is the magnetic field intensity. Magnetic structures that are suggestive of the modern core field include the high intensity flux lobes under North America and Eurasia, the longitudinal strip of intense field beneath Australia, and subequatorial patches of reversed flux that drift westward, which in the dynamo are advected by east-to-west azimuthal flow. These magnetic structures, particularly the high latitude patches, represent the tops of quasicolumnar convective structures extending deep into the outer core that become amplified by downwelling flow as they pass beneath regions with high CMB heat flux.

The effects of the CMB heterogeneity can be seen in the deviations from axisymmetry in the time average CMB magnetic field shown in Figure 3a, including higher intensity field lobes in the northern hemisphere at the longitudes where the CMB heat flux is maximum. Reduced versions of these lobes are also evident in the southern hemisphere, but there the non-axisymmetric structure merges into a single high latitude lobe, as found previously in dynamos using tomographic CMB heat flux conditions (Olson and Christensen, 2002). The radial velocity pattern in Figure 3b shows departures from axial symmetry induced by the CMB heterogeneity, particularly beneath Asia, superimposed on the stronger downwelling induced by the inner core tangent cylinder.

CMB heat flux heterogeneity is felt all the way to the ICB. Figure 3c shows the time average of the codensity flux on the ICB, contoured such that red corresponds to the largest flux and blue to the smallest. According to the definition (2), lateral variations in ICB codensity flux in this dynamo can be considered as a proxy for the lateral variations in the 
rate of inner core solidification. The large zonal variation in Figure 3c, with high codensity flux at low latitudes and low codensity flux at high latitudes is characteristic of the heat and light element fluxes produced by the columnar structure of the convection, which advects the codensity more efficiently outside the inner core tangent cylinder. However, the nonzonal variations in Figure $3 \mathrm{c}$ are products of the $\mathrm{CMB}$ heterogeneity. In addition to a spherical harmonic degree 2 modulation there is also a spherical harmonic degree 1 component, marked by a low latitude concentration of codensity flux with its maximum located in the Eastern hemisphere. This transformation of dominantly spherical harmonic degree 2 CMB heterogeneity into spherical harmonic degree 1 ICB heterogeneity by the flow in the outer core has been found previously in numerical dynamos (Aubert et al., 2008) and has been suggested as a driver for the hemispherical differences observed in the seismic structure of the inner core.

Additional effects of the CMB heterogeneity are evident in the time average codensity structure shown in Figure 4. The deviations from azimuthal symmetry in Figure 4a, most evident in the region just below the $\mathrm{CMB}$, are consequences of the lateral variations in CMB heat flux producing radial downflows while attenuating azimuthal motion at longitude bands where the CMB heat flux is highest, and producing radial upflows while enhancing azimuthal motion at longitude bands between these. The equatorial mean codensity profile in Figure 4b includes a thin layer just below the CMB in which the codensity gradient is slightly positive and therefore stable, a consequence of the equatorial mean CMB heat flux being subadiabatic. Although the stratification is locally stable, especially beneath the low CMB heat flux regions, the average stratification is practically neutral, as the global mean profile in Figure 4b demonstrates. We find that this type of patchwork stratification has little effect on the overall behavior of the dynamo. For example, Figure 3 shows that weak radial motions penetrate close to the CMB in many places in spite of the patchwork stratification. We note that these weak upwellings and downwellings are nevertheless strong enough to produce magnetic flux concentrations on the CMB that are morphologically similar to the flux concentrations in the present-day core field in Figure 2 and also appear in the time averaged core field (Johnson and Constable, 1995).

The structure of this dynamo would likely be different had we imposed stratification on the outer core, rather than allow stratification to develop from an initially adiabatic core as a consequence of the competition between positive and negative buoyancy fluxes originating 
at the ICB and CMB. Imposed stratification can be made arbitrarily strong, dividing the outer core convection into distinct layers for example (Nakagawa, 2011). With our method, stratification is dynamically limited by the magnitude of the stabilizing boundary flux, which in our case is relatively small.

\section{Mantle-driven evolution of the core}

The three mantle GCMs in Figure 1 show the same general trends in mean CMB heat flux with time. In each case the global mean CMB heat flux rises to $\bar{q}_{c m b}=85 \mathrm{~mW} \cdot \mathrm{m}^{-2}$ near 220 $\mathrm{Ma}$, then peaks at $88-94 \mathrm{~mW} \cdot \mathrm{m}^{-2}$ around $70 \mathrm{Ma}$, before falling to $81-86 \mathrm{~mW} \cdot \mathrm{m}^{-2}$ at present.

The minor differences in $\bar{q}_{c m b}$ prior to $220 \mathrm{Ma}$ are numerical, attributable to differences in the precision of the tracer methods that are used to track the compositional heterogeneity in the three cases. Overall, the variation between the three cases is generally smaller than the peakto-peak variation within a single case. For these three cases the mean and standard deviation of the 0-200 Ma total core heat flow correspond to $Q_{c m b}=13.1 \pm 1.3 \mathrm{TW}$. As discussed earlier, the CMB heat flow in mantle GCMs depends on the temperature on the CMB as well as transport properties in the mantle, particularly mantle viscosity and thermal conductivity. Other mantle GCMs by Zhang and Zhong (2011) examined the effects on CMB heat flow due to absence of the D" chemical layer, differences in mantle viscosity structure, changes in the Clapyeron slope of the transition zone phase transformations, as well as increase in the spreading rate of the Pacific oceanic plates. Varying these parameters yielded time average CMB heat fluxes generally higher than the preferred case, spanning the range 80$110 \mathrm{~mW} . \mathrm{m}^{-2}$, or approximately 12-17 TW. Similarly, Wu et al. (2011) obtained $Q_{c m b}=$ $13 \pm 3 \mathrm{TW}$ in their inversion of mantle lower mantle tomographic structure. Accordingly, for calculating the evolution of the core we focus on the range $Q_{c m b}=12-14 \mathrm{TW}$ as being representative of the past few hundred million years, but we consider cases in which $Q_{c m b}$ deviates from this range by as much as $\pm 4 \mathrm{TW}$. This covers the spread of core heat flow produced by other mantle GCMs that support chemical piles in the D"-layer (Nakagawa and Tackley, 2005, 2013; Zhang and Zhong, 2011).

The dynamo model results in the previous section demonstrate that the CMB heat flow predicted by mantle GCMs, although comparable to or slightly less than adiabatic, can produce dynamo magnetic field structures similar to what is observed in the present-day 
core field, provided no strong compositional layering is present. Obvious follow-up questions are: what are the implications for this state of the core going backward into the deep past? For how long is this thermal regime viable in terms of its ability to maintain the dynamo, and similarly, what is the age of the inner core implied by this thermal regime?

Figure 5 shows how the evolution of the core is modeled since the time of ICN. The solid curves represent the present-day adiabatic temperature profile $T_{a d}$ and light element concentration $\chi$, and the dotted curves are the same at the time of ICN. The dashed red curve is the melting curve in the core denoted by $T_{\text {melt }}$, the total heat loss from the core to the mantle at the $\mathrm{CMB}$ is denoted by $Q_{c m b}$, and the total heat production within the core by radioactive decay is denoted by $Q_{\text {rad }}$. In calculating the evolution of the core it is usually assumed that the inner core boundary is a phase equilibrium boundary between the solid inner core and the liquid outer core so that $T_{i c b}=T_{m e l t}$ at $r_{i c b}$, the radius of the ICB. We also assume, consistent with the results of our numerical dynamo, that the outer core is well-mixed and therefore the geotherm closely follows an adiabatic temperature profile $T_{a d}$, the light element concentration in the outer core is uniform, and that the adjustment time of the dynamics in the core is small compared to the timescale for changes in the thermal structure of the lower mantle and core, so that the outer core remains in a state of statistical thermal and compositional equilibrium with respect to $Q_{c m b}-Q_{\text {rad }}$ (Buffett et al., 1996; Nimmo, 2007).

With these assumptions, the rate of inner core growth in response to the cooling of the core can be written (Labrosse, 2003)

$$
\dot{r}_{i c b}=\frac{\left(Q_{c m b}-Q_{r a d}\right)}{P}
$$

where the $P=P_{l}+P_{g}+P_{s}$ is the sum of individual contributions to the core energy balance from latent heat release at the ICB, gravitational energy release, and secular cooling of the core, respectively. Expressions for the individual contributions to $P$ are given in the Supplementary Materials section in terms of core properties. Overall, $P$ is most sensitive to the difference between the gradients of the core adiabat $T_{a d}$ and the melting curve $T_{m e l t}$ at the ICB, i.e., the parameter

$$
\Theta=\left.\left(\frac{d T_{a d}}{d r}-\frac{d T_{m e l t}}{d r}\right)\right|_{\text {icb }}
$$

49 As shown in Figure 5, the combination of large $Q_{c m b}-Q_{r a d}$ and small $\Theta$ implies relatively fast inner core growth, whereas the combination of small $Q_{c m b}-Q_{\text {rad }}$ and large $\Theta$ implies 
relatively slow inner core growth.

Our procedure for calculating the evolution of the core and the inner core age consists of the following steps: We first define a range of CMB heat flow based on the mantle GCMs described above. Next, we backward integrate (9) starting from the present-day, tracking the evolution of the core to determine the ICN age, examining the widest plausible ranges of $Q_{c m b}, Q_{r a d}$, and $\Theta$, the latter calculated by varying the assumed melting temperature at the ICB, $T_{\text {melt }}\left(r_{i c b}\right)$, away from its nominal value given in Table 2 . Finally, we test the viability of the geodynamo across this parameter range by calculating from dynamo scaling laws the magnetic Reynolds number of outer core convection, to assess whether the core evolution model is consistent with maintaining the geodynamo both after and before ICN.

Implicit in the above procedure is the assumption that core heat flow statistics derived from mantle GCMs over the past $200 \mathrm{Ma}$ are applicable at earlier times, as far back as the ICN. In addition, we are assuming that the small change in core temperature over this time interval does not affect either the dynamics of the lower mantle or the heat transfer through the mantle, thereby allowing us to use a fixed temperature CMB boundary condition for the mantle GCMs.

To test the validity of these assumptions, we show in Figure 6 the variation of CMB temperature and inner core radius versus age for $Q_{c m b}=12$ and $14 \mathrm{TW}$ and zero radioactivity, $Q_{\text {rad }}=0$, calculated from the core evolution model described in the Supplementary Materials section using the parameters in Table 2. For these cases the decrease in the CMB temperature $T_{c m b}$ since ICN is approximately $94^{\circ} \mathrm{K}$ and the ICN age is 770 and $660 \mathrm{Ma}$, respectively. Figure 6 also shows the core evolution driven by the CMB heat flow from mantle GCM case 2 in Figure 1 reflected at 200 Ma then repeated periodically back in time, with 1 TW of heating from potassium-40 added to the outer core. This combination of thermal forcing increases the ICN age to 800 Ma. For these heat flows the core evolution model predicts outer core convective velocities of the order $10^{-3} \mathrm{~m} . \mathrm{s}^{-1}$, corresponding to convective overturn times of a few centuries. Clearly, the dynamic response time of the core is negligible compared to ICN age, and the decrease in CMB temperature since ICN is only $2 \%$, a negligible amount in terms of its effect on the mantle GCM. 


\section{Inner core nucleation age}

Figure 7 shows predicted ICN ages as functions of $Q_{c m b}$ and melting curve parameter $\Theta$ for assumed values of present-day core radioactive heat production $Q_{\text {rad }}$ of 0,1 , and $2 \mathrm{TW}$. In these calculations, the decay rate of radioactive potassium-40 was used. The boxes with dashed outlines delineate the parameter combinations that are allowed on the basis of our mantle GCM heat flow statistics and melting relations for inner core compositions (Anzellini et al., 2013) The lower limit of the dashed boxes correspond to a Grüneisen parameter of $\gamma=0.9$ and the upper limits corresponds to $\gamma=1.8$. The dotted lines indicate the $0-200 \mathrm{Ma}$ mean CMB heat flow from our mantle GCMs.

Without radioactive heating, ICN ages range from more than 1600 Ma for $Q_{c m b}=6$ TW to less than $400 \mathrm{Ma}$ for $Q_{c m b}=18 \mathrm{TW}$ (Figures 7a,b), but using just the allowed values of $Q_{c m b}$ and $\Theta$ limits this range to 400-950 Ma. As the present-day radioactive heat content increases, the predicted age of ICN also increases, but the change is rather small for the amounts of radioactive heating that are probable in the core. High-pressure partition experiments indicate solubility of potassium in core alloys (Bouhifd et al., 2007) but the upper limit on its heat production in the core appear to be substantially less than $1 \mathrm{TW}$ (Hirose et al., 2013; Watanabe et al., 2014). Similarly, high-pressure partition experiments on uranium (Malavergne et al., 2007) indicate that its maximum heat production in the core is also substantially less than one terawatt. Therefore, taking $1 \mathrm{TW}$ as an upper bound on total radioactive heat production in the core, the maximum ICN age within the dashed boxes in Figure 7c is about 1100 Ma.

There is an additional constraint on core evolution related to its ability to sustain the geodynamo, which further restricts inner core age. Since we know that the geomagnetic field has persisted since 3400 Ma at least (Tarduno et al., 2010) the energetics of the core must allow for dynamo action today, just after ICN, as well as before ICN. The shaded regions in Figure 7 denote parameter combinations for which the core is subcritical for convection-driven dynamo action today (unshaded), supercritical for dynamo action today (yellow), supercritical for dynamo action 50 Myr after ICN (brown), and supercritical for dynamo action just prior to ICN (red). These regions are defined in terms of a prediction of the magnetic Reynolds number of convection in the outer core based on scaling laws derived from the systematics of numerical dynamos (Christensen and Aubert, 2006). Here 
the predicted magnetic Reynolds number of the outer core $R m$ is calculated using a method developed by Aubert et al. (2009) in which

$$
R m \simeq 1.31 p^{0.42} \mathrm{Pm}
$$

where $p$ is the (dimensionless) power from convection available to drive the dynamo. The relationship between $p$ and core parameters is given in the Supplementary Material. The critical value for dynamo action in a fully convective outer core is $R m_{\text {crit }} \geq 40$ (Christensen et al., 1999); the criterion based on (11) used for the shadings in Figure 7 is $R m=100$.

The boundaries separating subcritical and supercritical dynamo regimes depend sensitively on the thermal conductivity of the core because the adiabatic heat flux, which controls thermal convection in the outer core, is proportional to thermal conductivity. The buoyancy flux at the CMB is thermal and depends on the global mean heat flux relative to the heat flux down the adiabatic gradient there. Accordingly, if core thermal conductivity is high, the average CMB heat flux in the core is subadiabatic and makes a negative contribution to convective power $p$. Strongly subadiabatic CMB conditions reduce $p$ to the point where $R m<R m_{\text {crit }}$, indicating dynamo failure. Furthermore, a key assumption used to derive (11), that the outer core is adiabatic (well-mixed) outside of boundary layers, is no longer valid in the strongly stratified regime, casting further doubt on the viability of such a convective dynamo.

In Figure 7a,b, two thermal conductivities are considered, $k=100$ and $130 \mathrm{~W} \cdot \mathrm{m}^{-1} \cdot \mathrm{K}^{-1}$. The lower value is representative of the core conductivity predicted by Zhang et al. (2015) on the basis of density functional theory (DFT) including electron-electron scattering; the higher value is more representative of DFT calculations without this effect (Pozzo et al., 2014). The left hand portion of every panel has $R m<R m_{\text {crit }}$, implying that, for the oldest inner core ages, the present-day core would be incapable of sustaining the geomagnetic field by thermochemical convection. The situation improves moving to the right Figure 7, where the present-day core is supercritical for convective dynamo action for most parameter combinations. Problems for the geodynamo reappear, however, when considering the state of the core shortly after and before ICN. The darkest (red) shadings in Figure 7 indicate $\left(Q_{c m b}, \Theta\right)$ combinations for which the core is supercritical for convective dynamo action just prior to ICN. This region includes only large $Q_{c m b}$-values and generally young inner core ages. Figures 7a,b show that the maximum inner core age for which the geodynamo would 
be supercritical prior to ICN with $Q_{r a d}=0$ are approximately $775 \mathrm{Ma}$ for k=100 W.m ${ }^{-1} \cdot \mathrm{K}^{-1}$, and for this $Q_{c m b} \geq 12 \mathrm{TW}$ is needed. For $\mathrm{k}=130 \mathrm{~W} \cdot \mathrm{m}^{-1} \cdot \mathrm{K}^{-1}$, the maximum IC age is only about $550 \mathrm{Ma}$, and in this case $Q_{c m b} \geq 16 \mathrm{TW}$ is needed before ICN. Figure 7c indicates the maximum IC age increases by only 80 Ma with $Q_{\text {rad }}=1$ TW.

To further demonstrate this point, we show in Figure $7 \mathrm{~d}$ the ICN ages predicted for $Q_{\text {rad }}=2 \mathrm{TW}$. Although this amount of radioactive heating is not supported by partition experiments or by cosmochemical considerations (McDonough, 2003) it is nevertheless of some theoretical interest because whole-Earth thermal history calculations reveal that the increase in heat production with age corresponding to this amount of potassium in the present-day core helps the geodynamo survive back to $3.4 \mathrm{Ga}$ (Driscoll and Bercovici, 2014). Nevertheless, it would increase the allowable IC age by only about $160 \mathrm{Ma}$, strengthening our inference of a young inner core. Unless the amount of core radioactive heating greatly exceeds current estimates, the ICN was a relatively recent event; within $800 \mathrm{Ma}$ if there is no radioactive heating in the core, and within $1100 \mathrm{Ma}$, even if radioactive heating is abundant. By the same token, our models permit inner core ages as young as $400 \mathrm{Ma}$.

\section{Implications for powering the geodynamo and inner core convection}

The combination of our mantle GCMs and the $k=100 \mathrm{~W} \cdot \mathrm{m}^{-1} \cdot \mathrm{K}^{-1}$ core evolution cases in Figure 7 provides a self-consistent (although non-unique) picture of core-mantle thermal interaction from the present-day backward in time to the ICN. With this combination, our mantle GCMs predict supercritical convective dynamo conditions at the present-day, just after ICN, and also just before ICN, although with much reduced power. In contrast, according to Figure 7b, our mantle GCMs do not provide enough heat flow to power the geodynamo by thermal convection prior to ICN if $k=130 \mathrm{~W} \cdot \mathrm{m}^{-1} \cdot \mathrm{K}^{-1}$. It is possible that CMB heat flow was larger before ICN compared to 0-200 Ma, but it seems coincidental that CMB heat flow would change appreciably just at the time of ICN. Another possibility is that CMB heat flow today is actually a lot larger than our mantle GCMs predict. Apart from implying a very young inner core - a Paleozoic or possibly Mesozoic ICN - the consequences of this situation have hardly been explored.

The results in Figure 7 also bear on the question of subsolidus thermal convection within 
the inner core, which depends on whether the temperature profile in the inner core is subadiabatic or superadiabatic. The thermal state of the inner core is governed by a competition between cooling at the ICB and diffusion of the inner core internal heat, with fast inner core growth and low thermal conductivity leading to steeper and hence less stable temperature profiles. Deguen et al. (2011) showed that the inner core temperature profile is expected to be superadiabatic if

$$
\frac{d r_{i c b}^{2}}{d t}>6 \kappa_{\text {ic }}\left(\frac{d T_{m e l t}}{d T_{a d}}-1\right)^{-1}
$$

where $d T_{\text {melt }} / d T_{a d}$ is the ratio of the Clapeyron slope $d T_{\text {melt }} / d P$ over the adiabatic gradient $d T_{a d} / d P$, and $\kappa_{\text {ic }}$ is the thermal diffusivity in the inner core. If the inner core is assumed to grow as $r_{i c b} \propto \sqrt{t}$ (Labrosse, 2014), a reasonable approximation to the growth curves in Figure 6 , then (12) can be re-written as a criterion on the maximum ICN age $\tau_{I C N}$ that would generate a superadiabatic temperature profile in the inner core:

$$
\tau_{I C N}<\frac{r_{i c b}^{2}}{6 \kappa_{\text {ic }}}\left(\frac{d T_{\text {melt }}}{d T_{a d}}-1\right)
$$

(Deguen et al., 2011).

The thermal conductivity in solid iron at inner core conditions is likely to be even larger than for liquid iron at CMB conditions, with some estimates exceeding $170 \mathrm{~W} \cdot \mathrm{m}^{-1} \cdot \mathrm{K}^{-1}$ (de Koker et al., 2012; Pozzo et al., 2012; Gomi et al., 2013; Pozzo et al., 2014), which corresponds to $\kappa_{\mathrm{ic}}>1.710^{-5} \mathrm{~m} . \mathrm{s}^{-2}$. Assuming this conductivity and using $d T_{\text {melt }} / d T_{a d} \simeq 1.6$, (13) gives the maximum ICN age for inner core superadiabaticity of $\tau_{I C N} \leq 270 \mathrm{Ma}$. As this maximum is smaller than our most extreme ICN age estimates, such high thermal conductivity implies that the inner core is thermally stably stratified and therefore subsolidus thermal convection in the inner core would be unlikely. In contrast, the lower conductivity value of $k=100$ $\mathrm{W} \cdot \mathrm{m}^{-1} \cdot \mathrm{K}^{-1}$ recently obtained by Zhang et al. (2015) leads to a different interpretation. With this lower conductivity the critical ICN age for subsolidus convection in the inner core increases to $\simeq 460 \mathrm{Ma}$. Given the range of ICN ages our mantle GCMs predict (400-1100 Ma), convection in the inner core becomes marginally possible.

\section{Implications for mantle circulation, past and future}

The core evolution calculations in the previous sections could be extended to greater age, however it would be necessary to couple the core evolution more directly to the mantle 


\section{${ }^{519}$ Acknowledgments} as we have regarding the time of ICN. prevail over that time.

evolution, allowing the CMB temperature to change with time, and in addition, assumptions would be needed regarding the surface tectonic boundary conditions and the possibility of mantle melting. Because it is not possible to reconstruct global plate distributions in the deep past and our mantle GCMs do not include melting, we have restricted our attention to the time since ICN. Coupled mantle-core thermal evolution calculations that do not make use of plate motions but do include time dependent mantle convection and dynamo thermodynamics (Nakagawa and Tackley 2013, 2014) generally come to the same conclusions

Not only has the geomagnetic field persisted for 3.4 Ga at least (Tarduno, 2010), there is no paleomagnetic evidence that the geodynamo ever shut off (Biggen et al., 2012). Assuming $k=100 \mathrm{~W} \cdot \mathrm{m}^{-1} \cdot \mathrm{K}^{-1}$ (Zhang et al., 2015), the time average core heat flow in our mantle GCMs is adequate to maintain convective dynamo conditions from the present-day to some time before inner core nucleation, although slightly more core heat flow would be needed for thermal convection in the deep past when the core temperature, the adiabatic gradient, and the rotation rate were higher. Although the plate tectonics Wilson cycle may only date back to $3 \mathrm{Ga}$ (Shirey and Richardson, 2011) the greater antiquity of the geodynamo implies that some form of global mantle circulation was operational before then, extracting heat from the core at rates comparable to or larger than the past 200 Ma. As for the future, our models predict that, at the present rate of heat loss to the mantle, a large part of the outer core will remain molten for more than one Gyr and supercritical convective dynamo conditions will

This research was supported by Frontiers in Earth System Dynamics grant EAR-1135382 from the National Science Foundation. We thank the two referees for insightful reviews. 
556

557

558

559

560

561

562

563

564

565

\section{References}

Amit, H., 2014. Can downwelling at the top of the Earth's core be detected in the geomagnetic secular variation? Phys. Earth Planet. Inter. 229, 110-121.

Andrault, D., Bolfan-Casanova, N., Lo Nigro, G., Bouhifd, M. A., Garbarino, G., Mezouar, M., 2011. Solidus and liquidus profiles of chondritic mantle: Implication for melting of the Earth across its history. Earth Planet Sci. Lett. 304, 251-259.

Anzellini, S., Dewaele, A., Mezouar, M., Loubeyre, P., Morard, G., 2013. Melting of iron at Earth's inner core boundary based on fast X-ray diffraction. Science 340, 464-467.

Aubert, J., Amit, H., Hulot, G., Olson, P., 2008. Thermochemical wind flows couple Earth's inner core growth to mantle heterogeneity. Nature 454, 758-762.

Aubert, J., Labrosse, S., Poitou, C., 2009. Modelling the palaeo-evolution of the geodynamo. Geophys. J. Int. 179, 1414-1428.

Biggin, A. J., Steinberger, B., Aubert, J., Suttie, N., Holme, R., Torsvik, T.H., van der Meer, D.G., van Hinsbergen, D.J.J., 2012. Possible links between long-term geomagnetic variations and whole-mantle convection processes. Nature Geoscience 5, 526 533.

Boehler, R., Chopelas, A., Zerr, A. 1995. Temperature and chemistry of the core-mantle boundary. Chem. Geol. 120, 199-205.

Bouhifd, M. A., Gautron, L., Bolfan-Casanova, N., Malavergne, V., Hammouda, T., Andrault, D., Jephcoat, A. P., 2007. Potassium partitioning into molten alloys at high pressure: Implications for Earth's core. Phys. Earth Planet. Inter. 160, 22-33.

Bower, D. J., Gurnis, M., Seton, M., 2013. Lower mantle structure from paleogeographically constrained dynamic Earth models. Geochem. Geophys. Geosys. 14(1), 44-63, doi:10.1029/2012GC004267.

Buffett, B. A., Huppert, H. E., Lister, J. R., Woods, A. W., 1996. On the thermal evolution of the Earth's core. J. Geophys. Res. 101, 7989-8006. 
Buffett, B. A., 2002. Estimates of heat flow in the deep mantle based on the power requirements for the geodynamo. Geophys. Res. Lett. 29, 1566.

Buffett, B. A. 2003. The thermal state of Earth's core. Science 299(5613), 1675-1677.

Buffett, B. A. 2007. A bound on heat flow below a double crossing of the perovskitepostperovskite phase transition. Geophys. Res. Lett. 34(17).

Buffett, B. A., 2014. Geomagnetic fluctuations reveal stable stratification at the top of the Earth's core. Nature 507(7493), 484-487.

Bull, A. L., Domeier, M., Torsvik, T. H., 2014. The effect of plate motion history on the longevity of deep mantle heterogeneities. Earth Planet. Sci. Lett. 401, 172-182.

Burke, K., Torsvik, T.H., 2004. Derivation of Large Igneous Provinces of the past 200 million years from long-term heterogeneities in the deep mantle. Earth Planet. Sci. Lett. 227(3-4), 531-538.

Burke, K., Steinberger, B., Torsvik, T.H., Smethhurst, M.A., 2008. Plume generation zones at the margins of large low shear velocity provinces on the core-mantle boundary. Earth Planet. Sci. Lett. 265, 49-60.

Christensen, U., Olson, P., Glatzmaier, G. A., 1999. Numerical modelling of the geodynamo: a systematic parameter study. Geophys. J. Int. 138(2), 393-409.

Christensen, U., Aubert, J., 2006. Scaling properties of convection-driven dynamos in rotating spherical shells and application to planetary magnetic fields. Geophys. J. Int. $166,97-114$.

Davies, G. F., 1988. Ocean bathymetry and mantle convection 1. Large-scale flow and hotspots. J. Geophys. Res. Solid Earth and Planets 93(B9), 10467-10480.

Deguen, R., Cardin, P., 2011. Thermo-chemical convection in Earth's inner core. Geophys. J. Int. 187, 1101-1118.

de Koker, N., Steinle-Neumann, G., Vlcek, V., 2012. Electrical resistivity and thermal conductivity of liquid Fe alloys at high $\mathrm{P}$ and T, and heat flux in Earth's core. Proc. Nat. Acad. Sci. 109, 4070-4073. 
Driscoll, P., Bercovici, D., 2014. On the thermal and magnetic histories of Earth and Venus: Influences of melting, radioactivity, and conductivity. Phys. Earth Planet Inter. 236, $36-51$.

Dziewonski, A. M., Lekic, V., Romanowicz, B. A., 2010. Mantle anchor structure: an argument for bottom up tectonics. Earth Planet. Sci. Lett. 299, 69-79.

Dziewonski, A. M., Anderson, D. L., 1981. Preliminary reference Earth model. Phys. Earth Planet. Inter. 25, 297-356.

Gessmann, C. K., Wood, B. J., 2002 Potassium in the Earth's core? Earth Planet. Sci. Lett. 200, 63-78.

Gomi, H., Ohta, K., Hirose, K., Labrosse, S., Caracas, R., Verstraete, M. J., Hernlund, J. W., 2013. The high conductivity of iron and thermal evolution of the Earth's core. Phys. Earth Planet. Inter. 224, 88-103.

Gubbins, D., Alfè, D., Masters, G., Price, G. D., Gillan, M., 2004. Gross thermodynamics of two-component core convection. Geophys. J. Int. 157, 1407-1414.

Helffrich, G., Kaneshima, S., 2010. Outer-core compositional stratification from observed core wave speed profiles. Nature 468, 807-809.

Hernlund, J. W., 2010. On the interaction of the geotherm with a post-perovskite phase transition in the deep mantle. Phys. Earth Planet. Inter. 180,(3-4), 222-234.

Hirose, K., Labrosse, S., Hernlund, J., 2013. Composition and State of the Core. Ann. Rev. Earth Planet. Sci. 41, 657-691.

Johnson, C., Constable C. G., 1995. The time-averaged geomagnetic field as recorded by lava flows over the last 5 Ma. Geophys. J. Int. 122, 489-519.

Jones, C. A., 2007. Thermal and compositional convection in the core. In: Treatise on Geophysics, vol. 8, ch 4, Olson, P., (ed.), Elsevier B.V., 131-186.

Labrosse, S., Poirier, J. P., Le Mouel, J. L., 2001. The age of the inner core. Earth Planet. Sci. Lett. 190, 111-123. 
Labrosse, S., 2002. Hotspots, mantle plumes and core heat loss. Earth Planet. Sci. Lett. 199 (1-2), 147-156.

Labrosse, S., 2003. Thermal and magnetic evolution of the Earth's core. Phys. Earth Planet. Inter. 140 127-143.

Labrosse, S., 2014. Thermal and compositional stratification of the inner core. Comptes Rendus Geoscience 314, 119-129.

Lay, T., Hernlund, J., Buffett, B. A., 2008. Core-mantle boundary heat flow. Nature Geosci. 1, 25-32.

Lay, T., Hernlund, J., Garnero, E. J., Thorne, M. S., 2006. A post-perovskite lens and D" heat flux beneath the central Pacific. Science 314, 1272-1276.

Lekic, V., Cottaar, S., Dziewonski, A., Romanowicz, B., 2012. Cluster analysis of global lower mantle tomography: A new class of structure and implications for chemical heterogeneity. Earth Planet Sci. Lett. 357, 68-77.

Leng, W., Zhong, S. J., 2008. Controls on plume heat flux and plume excess temperature, J. Geophys. Res., 113, B04408.

Lithgow-Bertelloni, C., Richards, M. A., 1998. Dynamics of Cenozoic and Mesozoic plate motion. Rev. Geophys. 36, 27-78.

Loper, D. E., 1978. The gravitationally powered dynamo Geophys. J. R. Astron. Soc. 54, 389-404.

Malavergne, V., Tarrida, M., Combes, R., Bureau, H., Jones, J., Schwandt, C., 2007. New high-pressure and high-temperature metal/silicate partitioning of $\mathrm{U}$ and $\mathrm{Pb}$ : Implications for the cores of the Earth and Mars. Geochim. Cosmochim. Acta 71 (10), 2637-2655.

Masters, G., Gubbins, D., 2003. On the resolution of density within the Earth. Phys. Earth Planet. Inter. 140, 159-167.

McDonough, W. F., 2003. Compositional model for the Earth's core. In Treatise on Geochemistry, Vol. 2: The Mantle and Core, ed. R.W. Carlson, pp. 547-68. Oxford: Elsevier-Pergamon. 
McNamara, A. K., Zhong, S. J., 2005. Thermochemical structures beneath Africa and the Pacific Ocean. Nature 437, 1136-1139.

Monnereau, M., Yuen, D.A., 2010. Seismic imaging of the D " and constraints on the core heat flux. Phys. Earth Planet. Inter. 180(3-4), 258-270.

Muller, R. D., Gaina, C., Roest, W. R., 2008. Age, spreading rates, and spreading asymmetry of the world's ocean crust. Geochemistry Geophysics Geosystems 9, Q04006. doi:10.1029/2007GC001743.

Murthy, V. R., van Westrenen, W., Fei, Y. W., 2003. Experimental evidence that potassium is a substantial radioactive heat source in planetary cores. Nature 323, 163-165.

Nakagawa, T., Tackley, P. J., 2005. Deep mantle heat flow and thermal evolution of the Earth's core in thermochemical multiphase models of mantle convection. Geochem Geophys. Geosyst. 6, Q08003.

Nakagawa, T., 2011. Effect of a stably stratified layer near the outer boundary in numerical simulations of a magnetohydrodynamic dynamo in a rotating spherical shell and its implications for Earth's core. Phys. Earth Planet. Inter. 187 342-352.

Nakagawa, T., Tackley, P.J., 2008. Lateral variations in CMB heat flux and deep mantle seismic velocity caused by a thermal-chemical-phase boundary layer in 3D spherical convection. Earth Planet. Sci. Lett. 271, 348-358.

Nakagawa, T,, Tackley, P. J., 2010. Influence of initial CMB temperature and other parameters on the thermal evolution of Earth's core resulting from thermochemical spherical mantle convection. Geochem. Geophys. Geosyst. 11 Q06001.

Nakagawa, T., Tackley, P. J., 2011. Effects of low-viscosity post-perovskite on thermochemical mantle convection in a 3D spherical shell. Geophys. Res. Lett. 38 L04309.

Nakagawa, T., Tackley, P. J., 2013. Implications of high core thermal conductivity on Earth's coupled mantle and core evolution. Geophys. Res. Lett. 40(11), 2652-2656.

Nakagawa, T., Tackley, P. J., 2014. Influence of combined primordial layering and recycled MORB on the coupled thermal evolution of Earth's mantle and core. Geochem., Geophys., Geosyst. 15(3), 619-633. 
Nimmo, F., 2007. Energetics of the Core. In Treatise on Geophysics, G. Schubert, Ed., Vol. 8, ch. 2, Elsevier B.V.

Nimmo, F., Alfe, D., 2006. Properties and evolution of the Earth's core and geodynamo, in Advances in Science: Earth Science, Sammonds P. R., Thompson J. M. T., eds., Imperial College Press, London.

Olson, P., Christensen, U.R., 2002. The time-averaged magnetic field in numerical dynamos with non-uniform boundary heat flow. Geophys. J. Int. 151, 809-823.

Olson, P., Deguen, R., Hinnov, L. A., Zhong, S., 2013. Controls on geomagnetic reversals and core evolution by mantle convection in the Phanerozoic. Phys. Earth Planet. Inter. 214, 87-103.

Perrillat, J.-P., Mezouar, M., Garbarino, G., Bauchau, S., 2010. In situ viscometry of highpressure melts in the Paris-Edinburgh cell: application to liquid FeS. High Pressure Research 30 (3), 415-423.

Poirier, J.-P., 2000. Introduction to the physics of the Earth's interior, 2nd Edition. Cambridge University Press.

Pozzo, M., Davies, C., Gubbins, D., Alf é, D., 2012. Thermal and electrical conductivity of iron at earth's core conditions. Nature 485, 355-358.

Pozzo, M., Davies, C. , Gubbins, D. , Alfé, D., 2014. Thermal and electrical conductivity of solid iron and iron-silicon mixtures at earth's core conditions. Earth Planet. Sci. Lett. 393, 159-164.

Roberts, P. H., Jones, C. A., Calderwood, A., 2003. Energy fluxes and Ohmic dissipation in the Earth's core. In Earth's core and lower mantle, Jones C A et al., eds., Taylor \& Francis.

Romanowicz, B., Gung, Y., 2002. Superplumes from the core-mantle boundary to the lithosphere: Implications for heat flux. Science 296, 513-516.

Rudolph, M., Zhong, S.J., 2015. History and dynamics of net rotation of the mantle and lithosphere. Geochem. Geophys. Geosyst., (submitted). 
Schubert, G., Turcotte, D., Olson, P., 2001. Mantle Convection in the Earth and Planets. Cambridge University Press, 940 pp.

Seton, M., Muller, R. D., Zahirovic, S., Gaina, C., Torsvik, T., Shephard, G., Talsma, A., Gurnis, M., Turner, M., Maus, S., and Chandler, M., 2012. Global continental and ocean basin reconstructions since 200 Ma. Earth Science Reviews 113, 212-270.

Shirey, S. B., Richardson, S. H., 2011. Start of the Wilson cycle at 3 Ga shown by diamonds from subcontinental mantle. Science 333(6041), 434-436.

Simons, M., Hager, B. H., 1997. Localization of the gravity field and the signature of glacial rebound. Nature 390, 500Â 504 .

Sleep, N. H., 1990. Hotspots and mantle plumes: Some phenomenology, J. Geophys. Res. Solid Earth and Planets. 95(B5), 6715-6736.

Stacey, F. D., Loper, D. E., 2007. A revised estimate of the conductivity of iron alloy at high pressure and implications for the core energy balance. Phys. Earth Planet. Inter. 161(1), 13-18.

Tarduno, J. A., Cottrell, R. D., Watkeys, M. K., Hofmann, A., Doubrovine, P. V., Mamajek, E. E., Liu, D. D., Sibeck, D. G., Neukirch, L. P., Usui, Y., 2010. Geodynamo, solar wind and magnetopause 3.4 to 3.45 billion years ago. Science 327, 1238-1240.

Tateno, S., Hirose, K., Sata, N., Ohishi, Y., 2009. Determination of post-perovskite phase transition boundary up to $4400 \mathrm{~K}$ and implications for thermal structure in D " layer. Earth Planet. Sci. Lett. 277(1-2), 130-136.

Torsvik, T.H., Smethhurst, M.A., Burke, K., Steinberger, B., 2006. Large igneous provinces generated from the margins of the large low-velocity provinces in the deep mantle. Geophys. J. Int. 167, 1447-1460.

Van der Hilst, R., de Hoop, M.V., Wang, P., Shim, S. H., Ma, P., Tenorio, L., 2007. Seismostratigraphy and thermal structure of Earth's core-mantle boundary region. Science 315, 1379 -1381. 
Van Hunen, J., Zhong, S.J., Shapiro, N. M., Ritzwoller, M.H., 2005. New evidence for dislocation creep from 3-D geodynamic modeling the Pacific upper mantle structure, Earth Planet. Sci. Lett. 238, 146-155.

Vocaldo, L., Alfe, D., Gillan, M. J., Price, G. D., 2003. The properties of iron under core conditions from frst principles calculations. Phys. Earth Planet. Inter. 140, 101-125.

Wang, Y., Wen, L., 2004. Mapping the geometry and geographic distribution of a very low velocity province at the base of the Earth's mantle, J. Geophys. Res. 109, B10305, doi:10.1029/2003JB002674.

Watanabe, K., Ohtani, E., Kamada, S., Sakamaki, T., Miyahara, M., Ito, Y., 2014. The abundance of potassium in the Earth's core. Phys. Earth Planet. Inter. 237, 65-72.

Wicht, J., 2002. Inner-core conductivity in numerical dynamo simulations. Phys. Earth Planet. Inter. 132, 281-302.

Wu B., Driscoll P., Olson P., 2011. A statistical boundary layer model for the mantle D" region. J. Geophys. Res. 116 B12112.

Zhang N., Zhong, S. J., 2011. Heat fluxes at the Earth's surface and core-mantle boundary since Pangea formation and their implications for the geomagnetic superchrons. Earth Planet. Sci. Lett. 306, 205-216.

Zhang, N., Zhong, S.J., Leng, W., Li, Z.X., 2010. A model for the evolution of the Earth's mantle structure since the Early Paleozoic. J. Geophys. Res. 115, B06401.

Zhang, P., Cohen, R.E., Haule, K., 2015. Effects of electron correlations on transport properties of iron at Earth's core conditions. Nature 517, 605-607. 
Table 1: Mantle GCM Parameters

\begin{tabular}{lll}
\hline Parameter & Notation & Value \\
\hline Superadiabatic temperature difference & $\Delta T_{m}$ & $2500 \mathrm{~K}{ }^{a}$ \\
Reference viscosities: plate, upper mantle, lower mantle & $\eta_{p, u, l}$ & $1200,0.6,100 \times 10^{20} \mathrm{Pa.s}{ }^{b}$ \\
Radioactive heat production & $h_{m}$ & $2.5 \times 10^{-8} W \cdot \mathrm{m}^{-3} \mathrm{c}$ \\
Reference density & $\rho_{m}$ & $3300 \mathrm{~kg} \cdot \mathrm{m}^{-3}$ \\
Initial D" dense layer thickness & $d_{0}$ & $250 \mathrm{~km}{ }^{d}$ \\
Initial D" density anomaly & $\Delta \rho_{d 0}$ & $82.5 \mathrm{~kg} \cdot \mathrm{m}^{-3} c$ \\
Heat capacity & $c_{m}$ & $1000 \mathrm{~J}^{-1} \cdot \mathrm{Kg}^{-1 f}$ \\
Thermal expansion coefficient & $\alpha_{m}$ & $2 \times 10^{-5} \mathrm{~K}^{-1} f$ \\
Thermal conductivity above the CMB & $k_{m}$ & $4 \mathrm{~W} \cdot \mathrm{m}^{-1} \cdot \mathrm{K}^{-1} c$ \\
Surface radius & $r_{\mathrm{surf}}$ & $6371 \mathrm{~km}$ \\
CMB radius & $r_{\mathrm{cmb}}$ & $3480 \mathrm{~km}$ \\
Viscosity activation energy & $E$ & $190 \mathrm{~kJ} \cdot \mathrm{mol}^{-1} e$
\end{tabular}

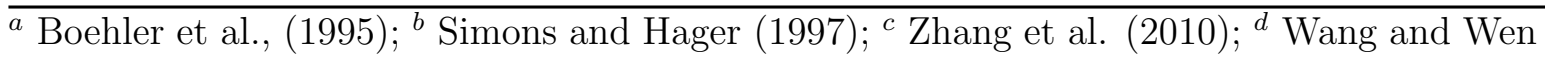
(2004); ${ }^{e}$ van Hunen et al. (2005); ${ }^{f}$ Schubert et al. (2001). 
Table 2: Core Evolution Parameters

\begin{tabular}{|c|c|c|}
\hline Parameter & Notation & Value [*Present-day] \\
\hline Density at core center & $\rho_{c}$ & $12500 \mathrm{~kg} \cdot \mathrm{m}^{-3} a$ \\
\hline Density at zero pressure & $\rho_{0}$ & $7500 \mathrm{~kg} \cdot \mathrm{m}^{-3}$ \\
\hline Compositional density jump at the ICB & $\Delta \rho$ & $500 \mathrm{~kg} \cdot \mathrm{m}^{-3 * b}$ \\
\hline Incompressibility at zero pressure & $K_{0}$ & $4.75 \times 10^{11} \mathrm{~Pa}$ \\
\hline Melting temperature at the ICB & $T_{\text {melt }}$ & $5500 \mathrm{~K}^{* c}$ \\
\hline Entropy of melting & $\Delta S$ & $120 \mathrm{~J} \cdot \mathrm{kg}^{-1} \cdot \mathrm{K}^{-1 d}$ \\
\hline Grüneisen parameter & $\gamma$ & $1.5^{e}$ \\
\hline Heat capacity & $c_{c}$ & $850 \mathrm{~J} \cdot \mathrm{kg}^{-1} \cdot \mathrm{K}^{-1} e$ \\
\hline Thermal expansion coefficient & $\alpha_{c}$ & $1.3 \times 10^{-5} \mathrm{~K}^{-1 e}$ \\
\hline Compositional expansion coefficient & $\beta$ & 1 \\
\hline Thermal conductivity at the CMB & $k$ & $100,130 \mathrm{~W} \cdot \mathrm{m}^{-1} \cdot \mathrm{K}^{-1}$ \\
\hline Density length scale & $r_{\rho}$ & $7400 \mathrm{~km}^{a}$ \\
\hline Temperature length scale & $r_{T}$ & $6040 \mathrm{~km}^{c}$ \\
\hline ICB radius & $r_{\text {icb }}$ & $1221 \mathrm{~km}^{* a}$ \\
\hline $\mathrm{CMB}$ radius & $r_{\mathrm{cmb}}$ & $3480 \mathrm{~km}^{a}$ \\
\hline Outer core light elements & $\chi$ & 9.8 wt. $\% * f$ \\
\hline Outer core kinematic viscosity & $\nu$ & $10^{-6} \mathrm{~m}^{2} \cdot \mathrm{s}^{-1} \mathrm{~g}$ \\
\hline
\end{tabular}

${ }^{a}$ Dziewonski and Anderson (1981); ${ }^{b}$ Masters and Gubbins (2003); ${ }^{c}$ Ancellini et al. (2013);

${ }^{d}$ Poirier (1990); ${ }^{e}$ Vocadlo et al. (2003); ${ }^{f}$ Hirose et al. (2013); ${ }^{g}$ Perriallt et al. (2010). 

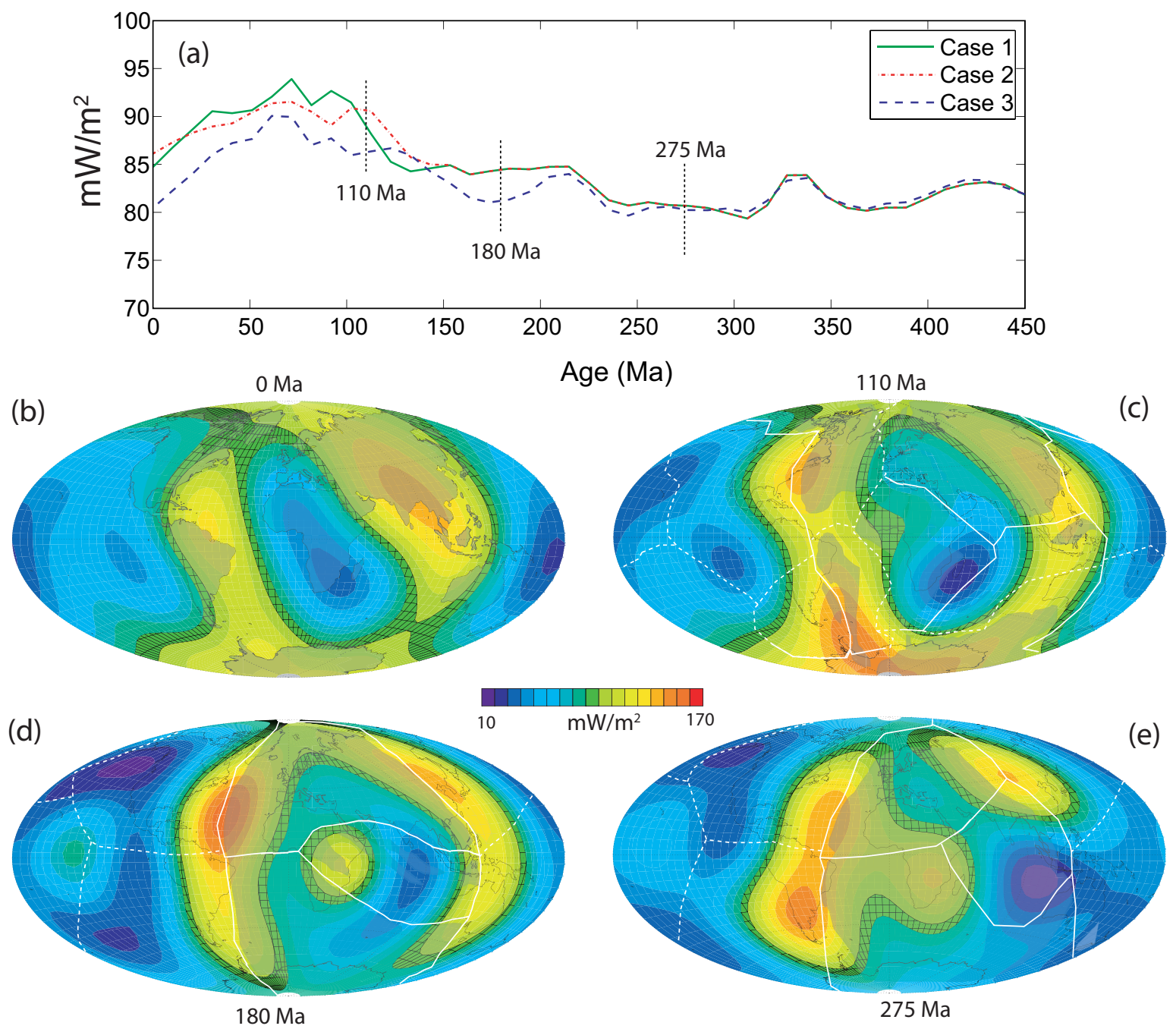

Fig 1

Figure 1. Heat flux on the core-mantle boundary (CMB) from mantle global circulation models (GCMs). (a): Time series of global mean CMB heat flux versus age from three mantle GCMs (Rudolph and Zhong, 2014) using plate reconstructions by Muller et al. (2008; 0-140 Ma; Case 1), Lithgow-Bertelloni and Richards (1998; 0-119 Ma; Case 2), and Seton et al., (2012; 0-200 Ma; Case 3). (b)-(e): Snapshots of CMB heat flux patterns for the present-day and the three Case 2 epochs labeled on the time series. The hashed contours enclose regions with CMB heat flux of $100 \mathrm{~mW} . \mathrm{m}^{-2}$ or more. Continents (shaded) and reconstructed plate boundaries (solid=convergent; dashed=divergent) are shown for reference. 

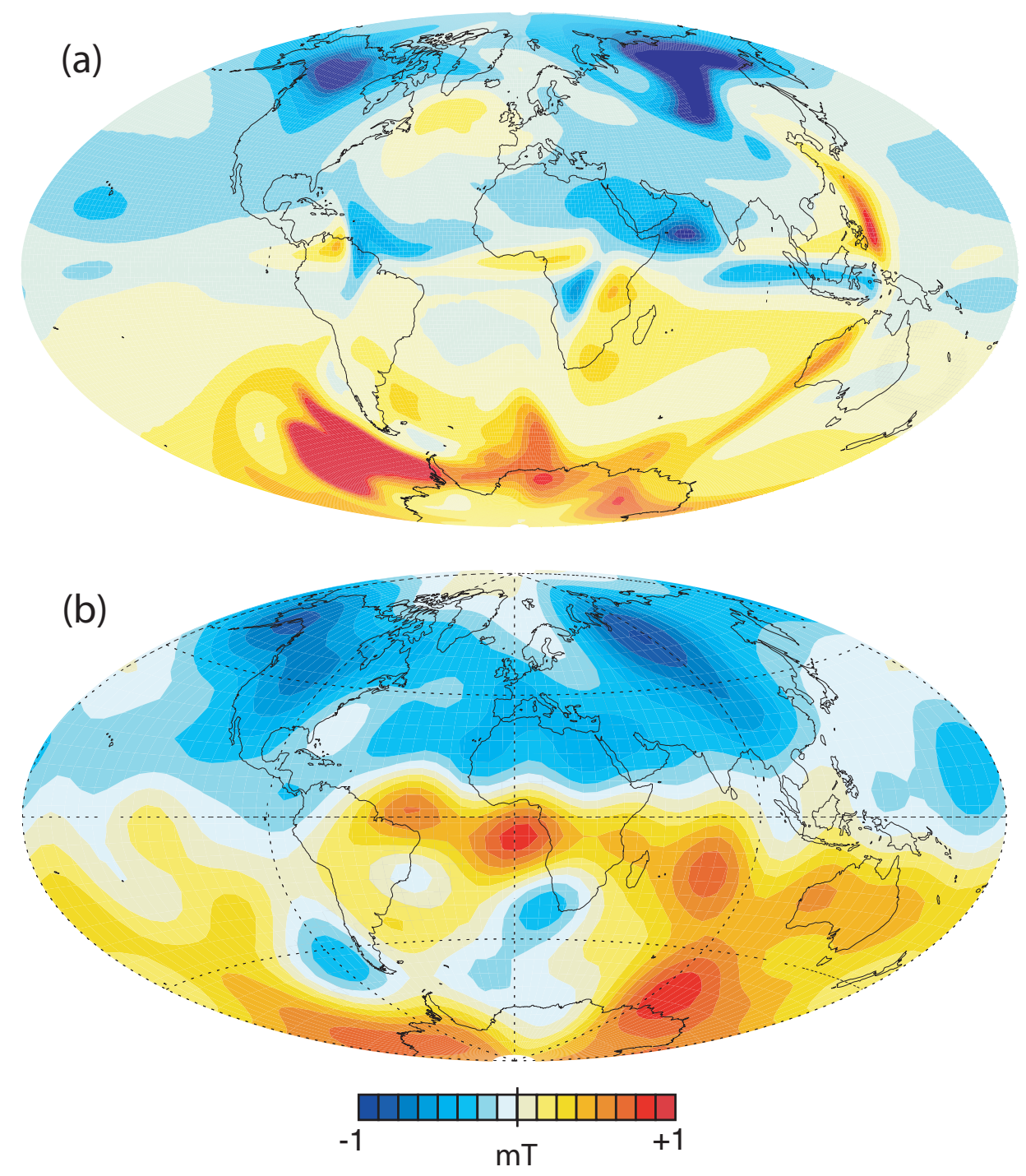

Fig 2

Figure 2. Comparison between (a) a snapshot of the radial magnetic field on the CMB from a numerical dynamo driven by the present-day 0 Ma pattern of CMB heat flux shown in Figure $1 \mathrm{~b}$ and (b) the present-day geomagnetic field intensity on the CMB in millitesla (mT) from core field model POMME 2008 (http://geomag.org/index.html). Dynamo magnetic field intensity is in dimensionless Elsasser units defined in the text. 

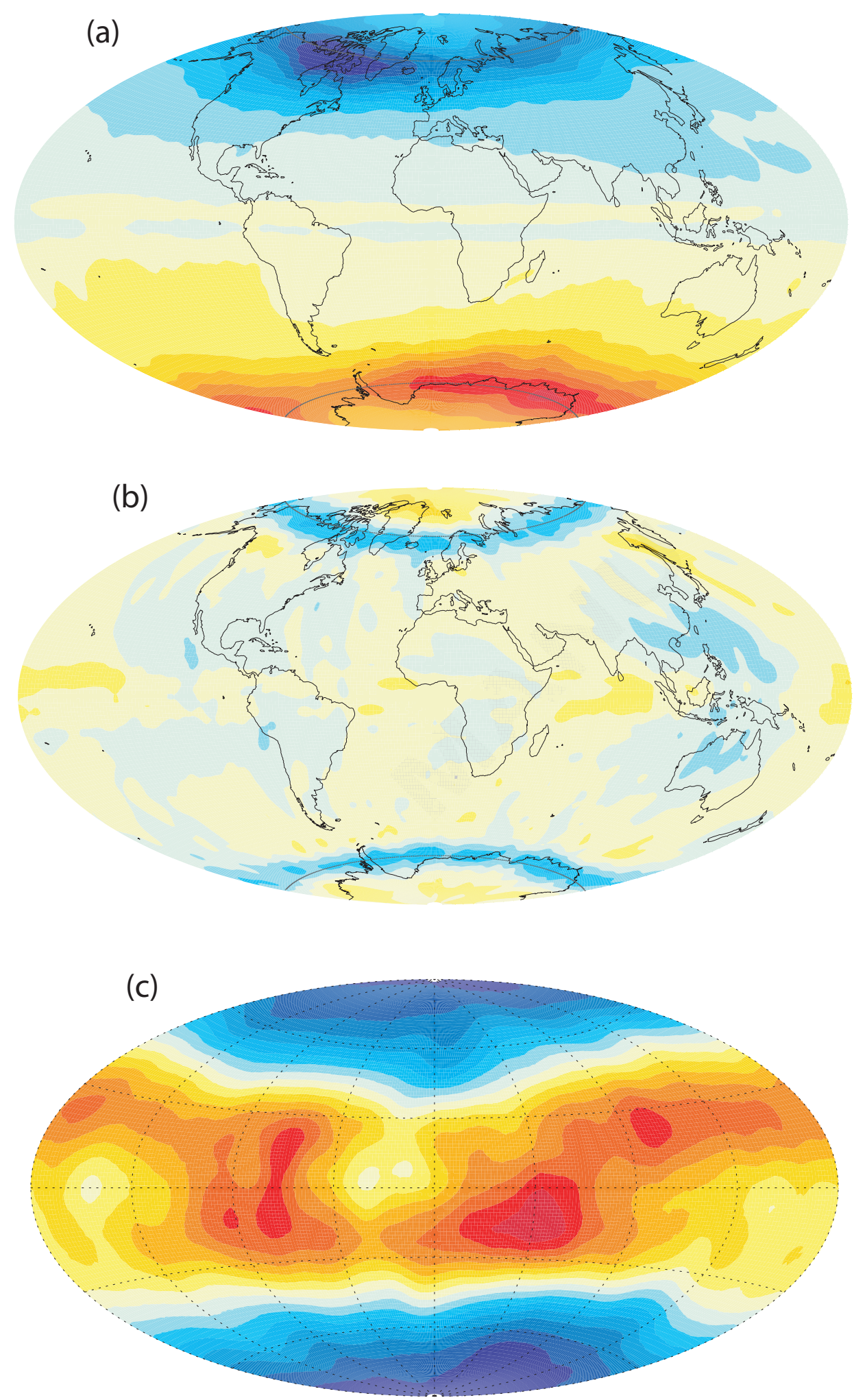

Fig 3

Figure 3. Time average structure of the numerical dynamo in Figure 2. (a) Time average radial magnetic field on the $\mathrm{CMB}$; contours in 0.2 dimensionless units. (b) Time average radial fluid velocity at a distance $z=0.05 D$ below the CMB, contours in magnetic Reynolds number units of 3. (c) Time average codensity flux on the ICB, contoured in 0.1 dimensionless units, oriented with maps (a) and (b). 
(a)

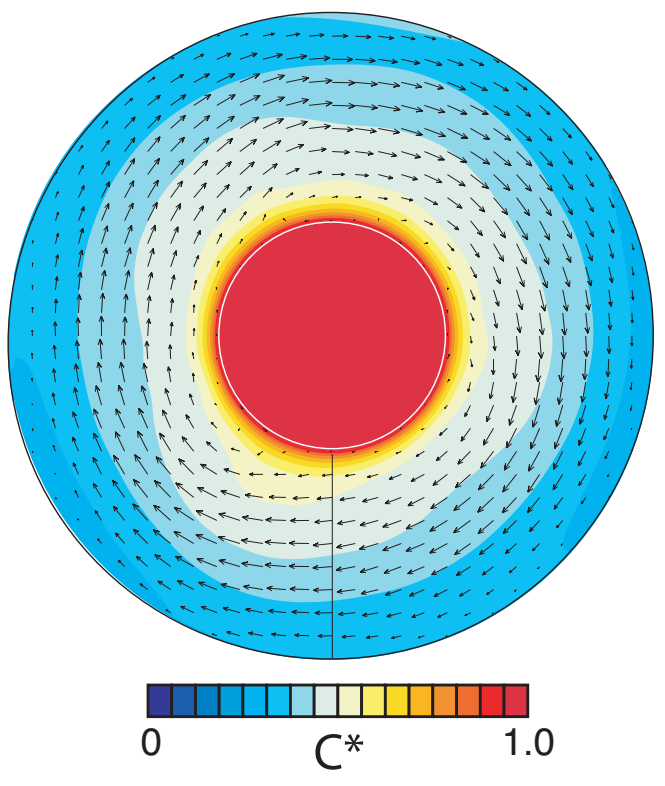

(b)

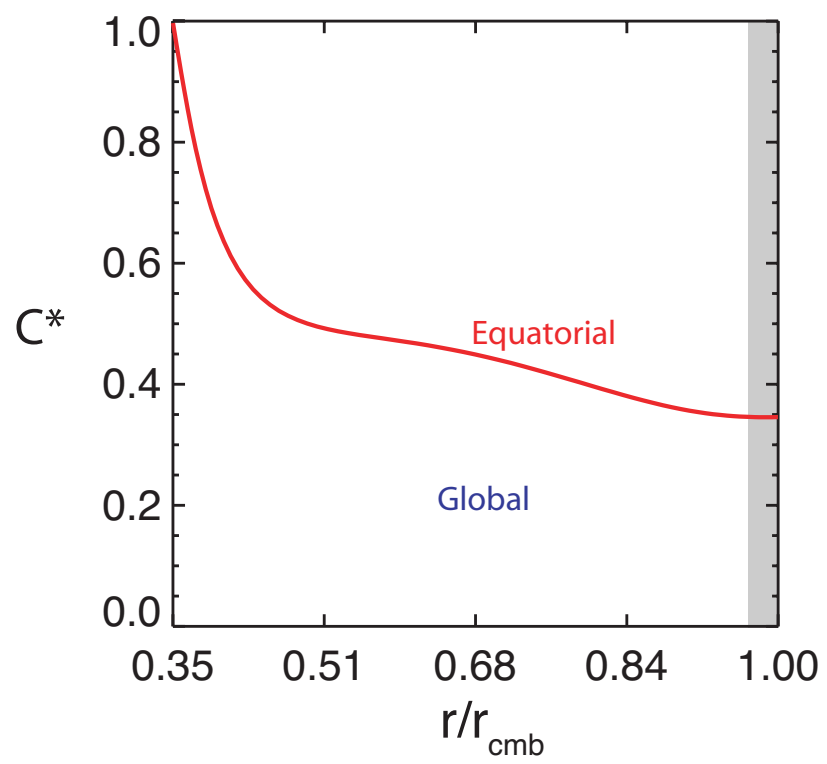

Fig 4

Figure 4. (a) Time average of the dimensionless codensity in the equatorial plane of the dynamo shown in Figures 2 and 3 with time average velocity arrows superimposed. Thin line marks $0^{\circ}$ longitude. (b) Global and equatorial averages of the radial variation of codensity from the same numerical dynamo, including the thin shaded region with a slightly stable stratification beneath the CMB in the equatorial average. 


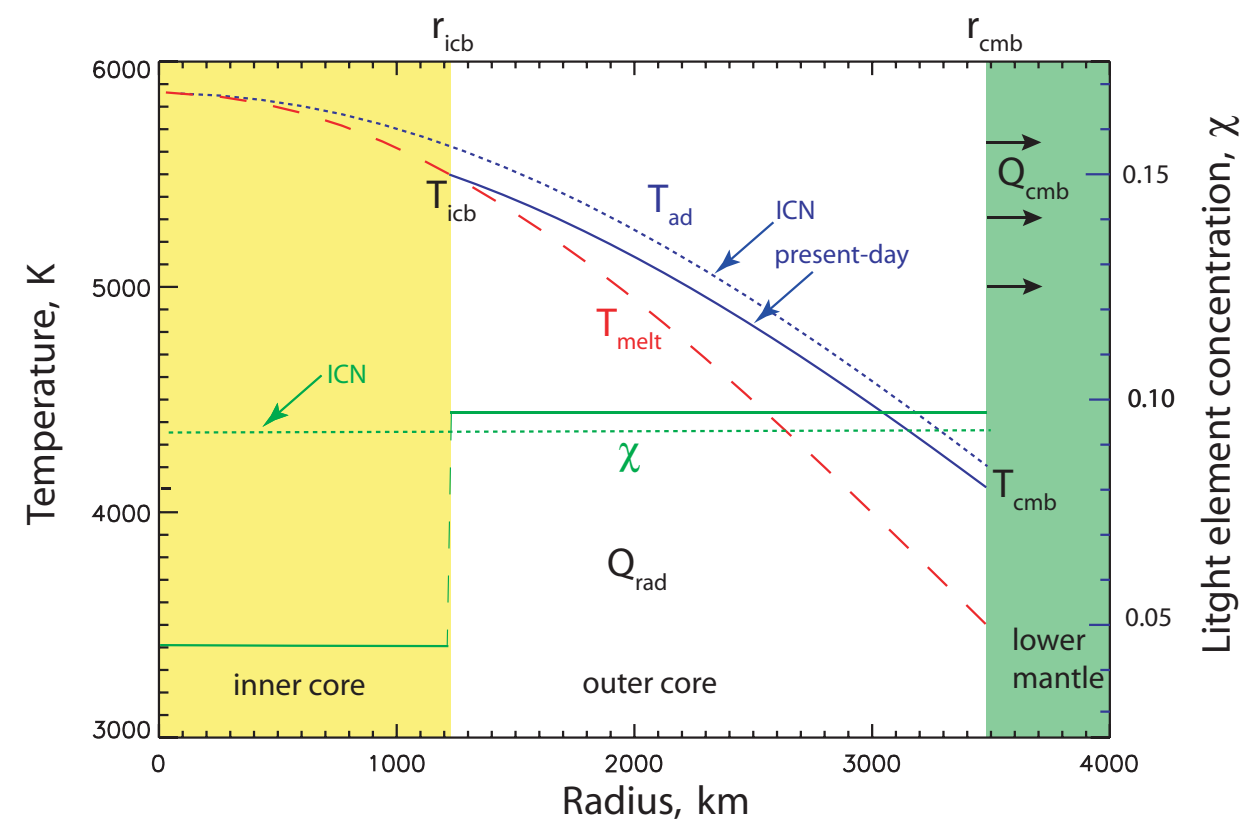

Fig 5

Figure 5. Evolution model of the core. Solid curves show present-day profiles of adiabatic temperature $T_{a d}$ and light element concentration $\chi$; dotted curves show these profiles at the time of inner core nucleation, ICN. Dashed curve $T_{\text {melt }}$ is a representative melting curve in the core. $Q_{c m b}$ and $Q_{r a d}$ are total CMB heat flow and internal radioactive heat production, respectively. 


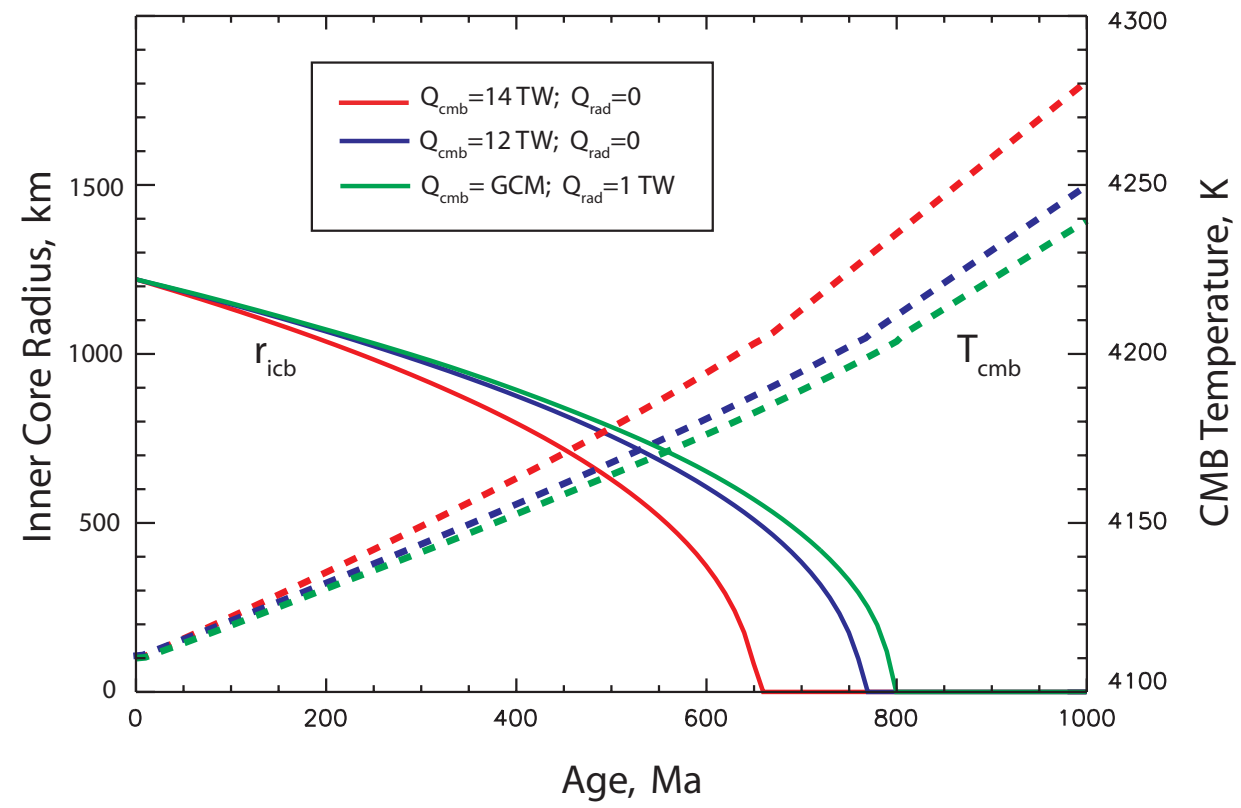

Fig 6

Figure 6. Evolution of the core for different values of the total CMB heat flow, assumed constant in time. $T_{c m b}$ and $r_{i c b}$ denote CMB temperature and inner core radius, respectively. 

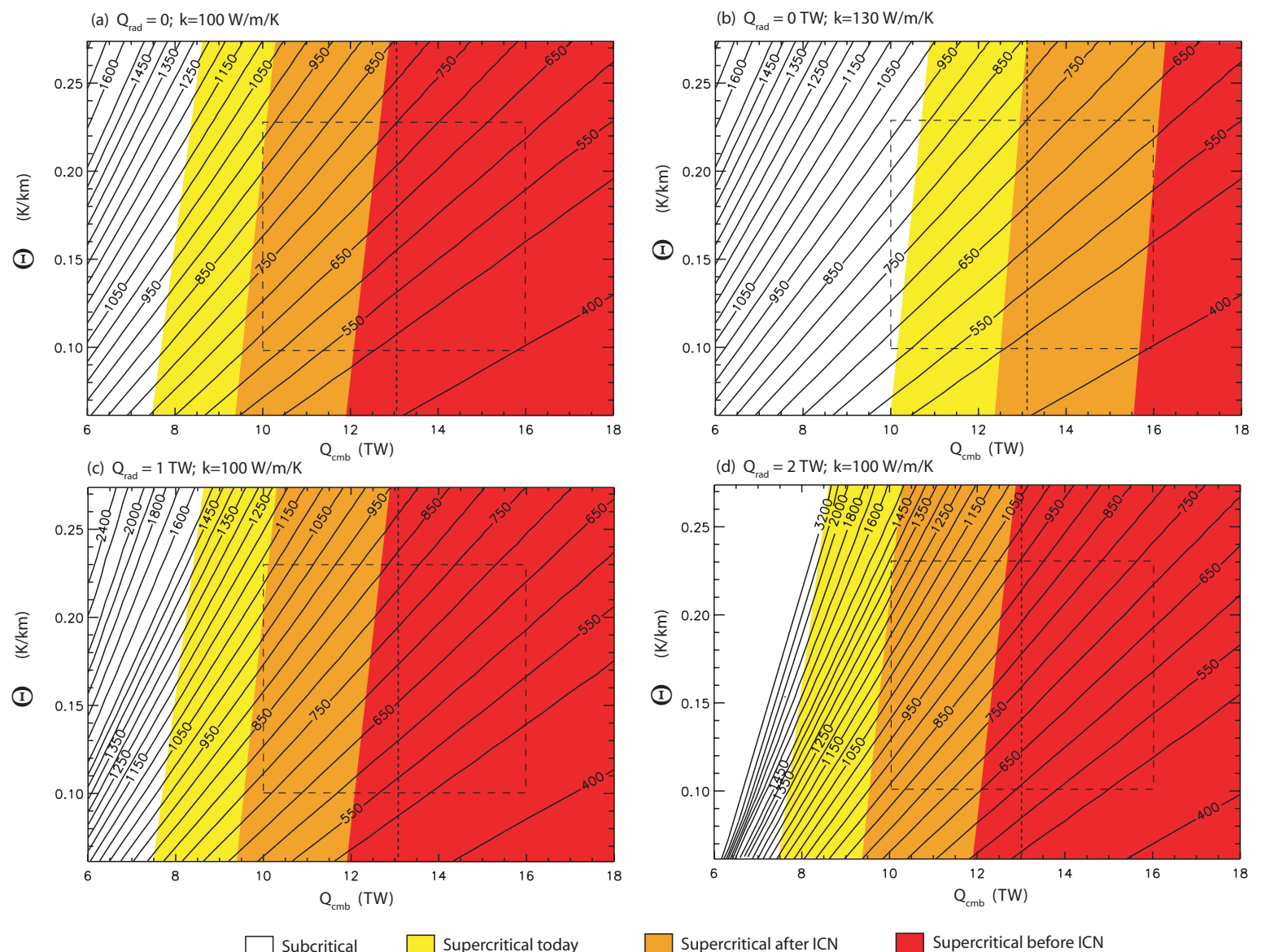

Fig 7

Figure 7. Predicted ages of inner core nucleation (ICN) in millions of years as a function of total CMB heat flow $Q_{c m b}$ and $\Theta$, the difference between the slope of the melting curve and the adiabat at the inner core boundary, calculated using different combinations of presentday potassium-40 radioactive heat production $Q_{\text {rad }}$ and outer core thermal conductivity $k$. Panels a, c, and d use $k=100 \mathrm{~W} \cdot \mathrm{m}^{-1} \cdot \mathrm{K}^{-1}$; Panel b uses $k=130 \mathrm{~W} \cdot \mathrm{m}^{-1} \cdot \mathrm{K}^{-1}$; Top row (a \& b) use $Q_{r a d}=0$; Bottom row: (c,d) use $Q_{r a d}=(1,2) \mathrm{TW}$, respectively. Shadings correspond to dynamo states: white $=$ subcritical; yellow $=$ supercritical today; light brown $=$ supercritical 50 Myr after ICN; red=supercritical just prior to ICN. Dashed boxes indicate allowed region based on mantle GCMs and core melting relations. Dotted lines indicate the time average $Q_{c m b}$ from our mantle GCMs. 